NASA TECHNICAL NOTE

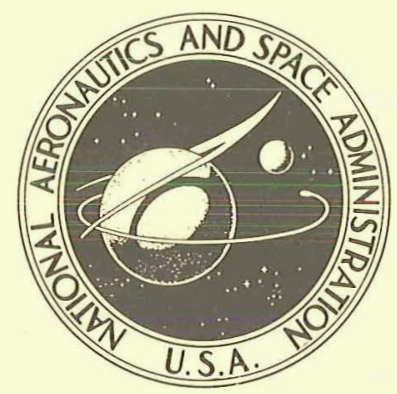

NASA TN D-5559

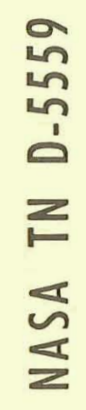

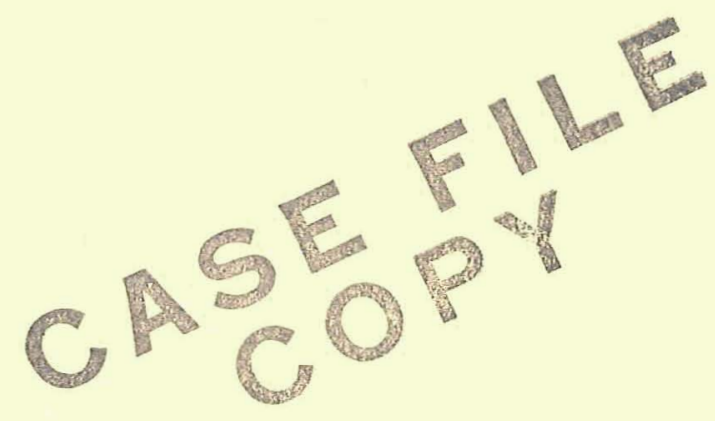

\title{
PREPARATION AND PROPERTIES OF IMIDE/PYRRONE COPOLYMERS
}

by Vernon L. Bell

Langley Research Center

Langley Station, Hampton, Va.

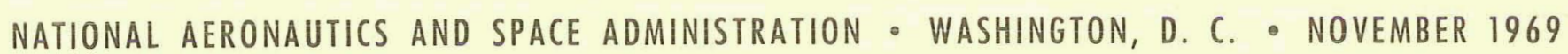




\begin{tabular}{|c|c|c|c|}
\hline $\begin{array}{l}\text { 1. Report No. } \\
\text { NASA TN D- } 5559\end{array}$ & 2. Government Accession No. & \multicolumn{2}{|c|}{ 3. Recipient's Cotalog No. } \\
\hline \multirow{2}{*}{\multicolumn{2}{|c|}{$\begin{array}{l}\text { 4. Title and Subtitle } \\
\text { PREPARATION AND PROPERTIES OF IMIDE/PYRRONE COPOLYMERS }\end{array}$}} & \multicolumn{2}{|l|}{$\begin{array}{r}\text { 5. Report Date } \\
\text { November } 1969\end{array}$} \\
\hline & & \multicolumn{2}{|c|}{ 6. Performing Organization Code } \\
\hline \multirow{2}{*}{$\begin{array}{l}\text { 7. Author(s) } \\
\text { Vernon L. Bell }\end{array}$} & & \multicolumn{2}{|c|}{$\begin{array}{l}\text { 8. Performing Organization Report No. } \\
L-6049\end{array}$} \\
\hline & & \multicolumn{2}{|c|}{$\begin{array}{l}\text { 10. Work Unit No. } \\
129-03-22-01-23\end{array}$} \\
\hline \multirow{2}{*}{\multicolumn{2}{|c|}{$\begin{array}{l}\text { 9. Performing Organization Name and Address } \\
\text { NASA Langley Research Center } \\
\text { Hampton, Va. } 23365\end{array}$}} & \multicolumn{2}{|c|}{ 11. Contract or Grant No. } \\
\hline & & \multicolumn{2}{|c|}{ 13. Type of Report and Period Covered } \\
\hline \multirow{2}{*}{\multicolumn{2}{|c|}{$\begin{array}{l}\text { 12. Sponsoring Agency Name and Address } \\
\text { National Aeronautics and Space Administration } \\
\text { Washington, D.C. } 20546\end{array}$}} & \multicolumn{2}{|c|}{ Technical Note } \\
\hline & & \multicolumn{2}{|c|}{ 14. Sponsoring Agency Code } \\
\hline \multicolumn{4}{|l|}{ 15. Supplementary Notes } \\
\hline \multicolumn{4}{|c|}{$\begin{array}{l}\text { 16. Abstract } \\
\text { Two series of copolymers containing imidazopyrrolone (Pyrrone) and imide groups were prepared by solu- } \\
\text { tion polymerization. The mechanical properties of thin films of the copolymers were measured and the films } \\
\text { showed a general increase in the tangent modulus and a decrease in elongation with increasing Pyrrone con- } \\
\text { tent. The copolymers were more resistant to degradation by strong acids and bases than the corresponding } \\
\text { polyimide. The thermal stabilities of the copolymers in air improved with increasing imide content, while the } \\
\text { thermal stabilities in a vacuum improved with increasing Pyrrone content. These copolymers represent a way } \\
\text { to utilize the useful properties of each class of homopolymers. }\end{array}$} \\
\hline \multicolumn{4}{|l|}{$\begin{array}{l}\text { 17. Key Words Suggested by Author(s) } \\
\text { Polymers } \\
\text { Imide } \\
\text { Pyrrone } \\
\text { Thermally stable polymers }\end{array}$} \\
\hline $\begin{array}{l}\text { 19. Security Classif. (of this report) } \\
\text { Unclassified }\end{array}$ & $\begin{array}{l}\text { 20. Security Classif. (of this page) } \\
\text { Unclassified }\end{array}$ & $\begin{array}{l}\text { 21. No. of Pages } \\
23\end{array}$ & $\begin{array}{r}\text { 22. Price* } \\
\$ 3.00\end{array}$ \\
\hline
\end{tabular}

${ }^{*}$ For sale by the Clearinghouse for Federal Scientific and Technical Information Springfield, Virginia 22151 


\title{
PREPARATION AND PROPERTIES OF IMIDE/PYRRONE COPOLYMERS
}

\author{
By Vernon L. Bell \\ Langley Research Center
}

\section{SUMMARY}

Two series of copolymers containing imidazopyrrolone (Pyrrone) and imide groups were prepared by solution polymerization. The mechanical properties of thin films of the copolymers were measured and the films showed a general increase in the tangent modulus and a decrease in elongation with increasing Pyrrone content. The copolymers were more resistant to degradation by strong acids and bases than the corresponding polyimide. The thermal stabilities of the copolymers in air improved with increasing imide content, while the thermal stabilities in a vacuum improved with increasing Pyrrone content. These copolymers represent a way to utilize the useful properties of each class of homopolymers.

\section{INTRODUCTION}

It has become apparent during the past decade that the conventional plastics developed during the first half of the 20th century have been unable to meet the more demanding needs of aeronautical and aerospace research and technology. However, two new classes of polymers, the polyimides (refs. 1 and 2) and the polyimidazopyrrolones (Pyrrones) (refs. 3 to 7), have been developed recently and show promise of meeting these critical materials needs. These new polymers derive their unique properties from the incorporation of a combination of aromatic and heterocyclic structural units, with their high orders of chemical, thermal, and radiation stability, into the long molecular chains that are the essentials of polymers. As the first commercially available heteroaromatic polymer to be offered in a variety of fabricated forms, the polyimides are currently being evaluated and even utilized in numerous aeronautical applications. The Pyrrones, a class of heteroaromatic polymers discovered at the Langley Research Center, represent an extension of the scheme of fusing aromatic and heterocyclic structural units into polymers of the ladder or two-strand variety that begin to approach the general structure of graphitic materials.

Though close similarities in the properties of the two polymer classes exist, there are also features unique to each class. The polyimides are considered to be essentially linear because of their solubilities in fuming nitric acid (ref. 2). However, the Pyrrones, 
which are prepared by virtually the same solution polymerization technique as the polyimides, are virtually insoluble in strong acidic solvents (ref. 7); this insolubility suggests a certain element of nonlinearity by reason of cross-linked sites. Compared with the polyimide films, the Pyrrone films exhibit high tangent moduli and low elongations, which are indicative of greater rigidity of the polymer chains. Thermogravimetric behavior of the two classes in a vacuum also shows a difference, the Pyrrones demonstrating lower weight losses in the extreme temperature range of $873^{\circ}$ to $1173^{\circ} \mathrm{K}\left(600^{\circ}\right.$ to $\left.900^{\circ} \mathrm{C}\right)$.

Either or both of these two polymer classes could quite possibly be used in specific aerospace or aeronautical applications. However, it was thought that by combining the two polymer types by copolymerization, a series of copolymers might be obtained that would have a range of properties. The resulting versatility can be imagined; for example, consider the properties that a polymer film must have in order to perform as a cell separator in an alkaline battery. For this end use, a Pyrrone film would probably resist the chemical action of the caustic electrolyte yet would likely be too brittle to serve as an unsupported membrane. Even though the polyimides are quite flexible as films, they are known to be dissolved by caustics. The solution could be to employ a copolymer of Pyrrone and polyimide if the two desirable properties of each class, resistance to alkali and film flexibility, could be merged into the copolymer.

In order to establish the scope of the properties that could be realized by copolymerization, two chemically differing series of copolymers were prepared covering the range of composition from a pure Pyrrone to a pure polyimide with various intermediate

copolymer compositions. The copolymers were then studied from the standpoint of the solution properties of the intermediate prepolymers, the chemical resistance of the cured films, and the mechanical properties of the films.

\section{SYMBOLS AND ABBREVIATIONS}

BTDA $3,3^{\prime}, 4^{4} 4^{\prime}$-benzophenone tetracarboxylic dianhydride

DAB $\quad 3,3^{\prime}$-diaminobenzidine

DMAc N,N-dimethylacetamide

$\mathrm{N} \quad$ normality, equivalent weights/decimeter 3

$\mathrm{n} \quad$ degree of polymerization

ODA $\quad \mathrm{p}, \mathrm{p}^{\prime}$-oxydianiline 
PMDA pyromellitic dianhydride

R.H. relative humidity

TADPO $3,3^{\prime}, 4,4^{\prime}$-tetraaminodiphenyl ether

$\eta_{\text {int }} \quad$ intrinsic viscosity, deciliters/gram

\section{EXPERIMENTAL PROCEDURES}

The schematic representations for the reactions leading to both Pyrrone polymers and polyimides are given in equations (A1) and (A2), respectively, in appendix A. The two copolymer series were prepared by the reactions illustrated by equations (A3) and (A4) in appendix A. Pyromellitic dianhydride (PMDA), p, $\mathrm{p}^{\prime}$-oxydianiline (ODA), and $3,3^{\prime}, 4^{4} 4^{\prime}$-tetraaminodiphenyl ether (TADPO) were used as the starting materials for the series of copolymers that were prepared by the reaction shown in equation (A3). This series of copolymers is referred to in this report as the PMDA-ODA/TADPO series. The second group of copolymers, which is represented by equation (A4), was prepared by utilizing $3,3^{\prime}, 4^{4} 4^{\prime}$-benzophenone tetracarboxylic dianhydride (BTDA), $3,3^{\circ}$-diaminobenzidine (DAB), and ODA as the basic chemicals. This series is referred to as the BTDA-ODA/DAB series. The numerical ratios appearing in equations (A3) and (A4) indicate the relative amounts of diamines (ODA) and tetraamines (TADPO and DAB) used to prepare the copolymers.

\section{Polymerizations}

A summary of the polymerizations leading to the PMDA-ODA/TADPO copolymers is given in table I, and a summary of the polymerizations for the BTDA-ODA/DAB copolymers is listed in table II. The purification of the various monomers is given in appendix B. Detailed procedures for the synthesis of the copolymers are given in the following sections.

PMDA-ODA/TADPO (100/0).- The PMDA-ODA/TADPO (100/0) control polyimide was prepared by the addition of 4.00 grams of solid PMDA to a stirred solution (highspeed household blender) of 4.00 grams of ODA in $60 \mathrm{~cm}^{3}$ of $\mathrm{N}, \mathrm{N}$-dimethylacetamide (DMAc). After 15 minutes, all the PMDA had dissolved and the temperature of the solution had increased to between $308^{\circ}$ and $313^{\circ} \mathrm{K}\left(35^{\circ}\right.$ and $\left.40^{\circ} \mathrm{C}\right)$. A solution of 0.55 gram of PMDA in $14 \mathrm{~cm}^{3}$ of DMAc was added dropwise to the stirred polymer solution until the desired consistency was obtained. The measured viscosity of the resulting prepolymer is presented in table I. 
PMDA-ODA/TADPO $(90 / 10,75 / 25,50 / 50,25 / 75,0 / 100)$. - The PMDA-ODA/TADPO copolymers $(30 / 10,75 / 25,50 / 50,25 / 75)$ and the PMDA-ODA/TADPO (0/100) control Pyrrone were prepared by the following procedure, which is illustrated for the $90 / 10$ copolymer. A solution of 4.00 grams of PMDA in $30 \mathrm{~cm}^{3}$ of DMAc was added to a rapidly stirred solution of 3.60 grams of ODA and 0.46 gram of TADPO in $35 \mathrm{~cm}^{3}$ of DMAc. The reaction resulted in heating of the polymer solution to between $308^{\circ}$ and $313^{\circ} \mathrm{K}\left(35^{\circ}\right.$ and $\left.40^{\circ} \mathrm{C}\right)$. After the resulting solution had been stirred for 15 minutes, a solution of 0.55 gram of PMDA in $10 \mathrm{~cm}^{3}$ of DMAc was added dropwise. This total addition of 4.55 grams of PMDA resulted in a viscous polymer solution $\eta_{\text {int }}=1.65 \mathrm{dl} / \mathrm{g}$ in DMAc at $298^{\circ} \mathrm{K}\left(25^{\circ} \mathrm{C}\right)$.

BTDA-ODA/DAB (100/0, 75/25, 50/50, 25/75, 0/100).- The BTDA-ODA/DAB (100/0) control polyimide was synthesized by the same method (addition of solid dianhydride) as that used to prepare the PMDA-ODA/TADPO (100/0) control polyimide, and the BTDA-ODA/DAB copolymers $(75 / 25,50 / 50,25 / 75)$ and the BTDA-ODA/DAB (0/100) control Pyrrone were prepared by the same method (addition of dianhydride solution) as that used for preparation of the corresponding PMDA-derived copolymers.

\section{Film Preparation}

Films were obtained by solvent-casting the previously described polymer solutions onto glass plates, drying them at $373^{\circ} \mathrm{K}\left(100^{\circ} \mathrm{C}\right)$ for 2 hours, and curing them at $448^{\circ} \mathrm{K}$ $\left(175^{\circ} \mathrm{C}\right)$ for 1 hour and then at $573^{\circ} \mathrm{K}\left(300^{\circ} \mathrm{C}\right)$ for 1 additional hour. The resulting films were easily stripped from the glass plates and used for testing. The copolymer films were light yellow for the polyimides and progressed through orange shades with increasing Pyrrone content to the deep red color of the pure Pyrrone. The infrared spectra of the PMDA-ODA/TADPO copolymers, which were obtained in order to confirm the composition, appeared to be composites of the spectra of the two homopolymers: PMDA-ODA polyimide (ref. 2) and PMDA-TADPO Pyrrone (ref. 3). The intensity of the absorption bands at $5.63 \mu, 9.85 \mu$, and $16.6 \mu$ in the copolymer spectra increased with increasing imide (ODA) content, while the intensity of the bands at $6.19 \mu$ and $10.4 \mu$ increased with increasing Pyrrone (TADPO) content.

\section{RESULTS AND DISCUSSION}

\section{Mechanical Properties}

The mechanical properties of the films derived from the two series of copolymers were determined by the technique described in appendix $\mathrm{C}$. They are listed in tables III and IV and are pictured in figures 1 and 2 . The films varied in thickness from about 0.80 to $1.30 \mathrm{mils}(0.02$ to $0.03 \mathrm{~mm})$, although the individual test specimens for each film composition were the same thickness to within $0.10 \mathrm{mil}(0.0025 \mathrm{~mm})$. 
The properties of both series of films reflect the changes to be expected for a progressive stiffening of the polymer chains (increased film brittleness) with increasing Pyrrone (TADPO and DAB) content. The tangent moduli show a general increase and the elongations show a corresponding decrease. Although less consistent, the yield and tensile strengths of the two series of films increase with increasing Pyrrone content.

\section{Thermal Stability}

The thermal stabilities of the two copolymer series were determined by heating the films in a vacuum using the thermogravimetric analytical procedure. The results are shown in figure 3 for the PMDA-ODA/TADPO films and in figure 4 for the BTDAODA/DAB films. The general effect of copolymerization was an increase in the thermal stability over that of the polyimides, since for both series, the char yields at $1073^{\circ} \mathrm{K}$ $\left(800^{\circ} \mathrm{C}\right)$ were greater for the copolymers containing more Pyrrone structure (higher percentages of TADPO and DAB).

The thermal stabilities of the copolymers were also measured by thermogravimetric analysis in an environment of air. The relative oxidative stabilities are pictured in figure 5 for the PMDA-ODA/TADPO films and in figure 6 for the BTDA-ODA/DAB films. The thermal stability of the PMDA-derived series increases slightly with increasing imide content. Because of the close similarities of the thermogravimetric curves obtained for the BTDA-derived copolymers, they have all been represented as falling within the shaded area outlined by the curves for the BTDA-ODA/DAB (100/0) control polyimide and the BTDA-ODA/DAB (0/100) control Pyrrone films. For a comparison of the two series, the curve for the control polyimide of the PMDA-derived series has been indicated by a dashed line.

The effect of copolymerization on the oxidative stability of the PMDA-ODA/TADPO copolymer series is pictured in a different manner in figure 7. Here, the temperatures of maximum rates of decomposition of the copolymers, as determined by differential thermal analysis, are plotted as a function of Pyrrone/imide (TADPO/ODA) content, and it is apparent that the temperatures of the maximum rates of decomposition for the copolymers increase with increasing imide content. A corresponding evaluation of the BTDA-ODA/DAB series was not made.

Thus, it can be concluded that even though the thermal stabilities of the imide/Pyrrone copolymers in a vacuum environment are greater with increasing Pyrrone content, the effect of copolymerization on the oxidative stabilities is quite the opposite; that is, the copolymers with the higher imide content are superior in a thermal air environment. 


\section{Chemical Stability}

The resistance of the imide/Pyrrone copolymers to strong caustic and acidic reagents was more similar to that of the pure Pyrrones (ref. 7) than to that of the polyimides (ref. 2). As little as 10 percent of the Pyrrone structure resulted in a marked change in chemical resistance, as shown in table $V$ for the PMDA-ODA/TADPO series. The reason for such an enhancement of the chemical resistance by the inclusion of Pyrrone structures has not been determined with certainty. The likelihood that crosslinking is the main factor is strong. However, as little as 10 percent Pyrrone structure (PMDA-ODA/TADPO (90/10)) results in a marked change in insolubility while the mechanical properties of the film are not markedly changed from those of the pure polyimide film (PMDA-ODA/TADPO (100/0)), as would be expected from a large amount of cross-linking; therefore, some doubt is cast on the validity of the cross-linking explanation.

An experiment that not only emphasized the chemical stability of the imide/Pyrrone copolymers, but also substantiated their copolymeric nature involved soaking $1-$ mil (0.0254-mm) films of the PMDA-ODA/TADPO $(75 / 25,25 / 75)$ copolymers in yellow fuming nitric acid. After 24 hours, the $75 / 25$ and $25 / 75$ copolymers had lost only 5 percent and 2 percent of their weights, respectively. In contrast, a film prepared from a simple mixture of 75 percent PMDA-ODA polyimide and 25 percent PMDA-TADPO Pyrrone prepolymers lost 57 percent of its weight after identical treatment. This result proves that the copolymers were not mere physical mixtures.

\section{Water Absorption}

The regular variation of the properties of the copolymers with respect to their constituent groups (Pyrrone and imide) was further exemplified by the amounts of water absorbed readily by thin films of the two copolymer series. The weight percent of water absorbed at $298^{\circ} \mathrm{K}\left(25^{\circ} \mathrm{C}\right)$ and 100 percent relative humidity are plotted as a function of the amount of Pyrrone content (TADPO and DAB) for the PMDA-ODA/TADPO series in figure 8 and for the BTDA-ODA/DAB series in figure 9 . Though the increased absorptivity of water caused by copolymerization of the polyimides with the Pyrrones would be less than desirable for such end uses as electrical insulation, there can also be imagined uses wherein the hydrophilic nature would be desirable, as in membranous end uses.

\section{CONCLUDING REMARKS}

It has been demonstrated that polyimides and Pyrrone polymers can be copolymerized to give materials that have a potential for use in aeronautical and aerospace applications. The characteristics of the resultant copolymers can be varied to give a versatile 
selection of properties. This variation in properties is generally regular in dependence upon the compositions of the copolymers between the extremes of the pure polyimides and the pure Pyrrones. An example of the value of this variability in properties is shown by the moderation of the inherent brittleness of Pyrrone films by the incorporation of certain quantities of imide groups into the polymer by copolymerization.

\section{Langley Research Center,}

National Aeronautics and Space Administration,

Langley Station, Hampton, Va., October 1, 1969. 


\section{APPENDIX A}

\section{ANALYSIS OF CHEMICAL REACTIONS}

The schematic reactions of aromatic dianhydrides (for example, PMDA) with aromatic tetraamines (for example, TADPO) and aromatic diamines (for example, ODA) leading to Pyrrones and polyimides are depicted in equations (A1) and (A2), respectively.

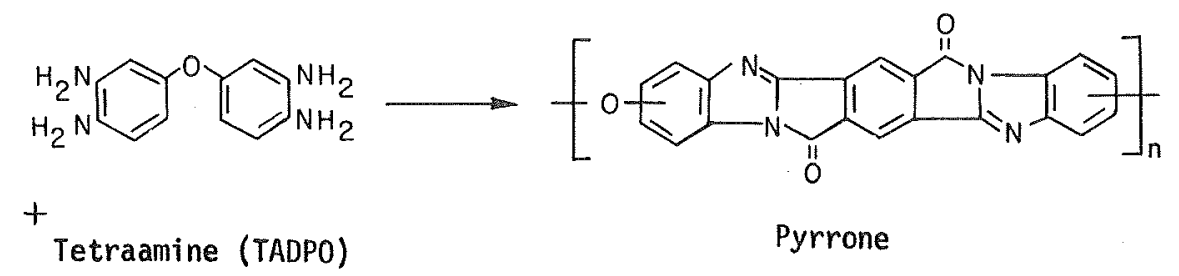<smiles>O=c1oc(=O)c2cc3c(=O)oc(=O)c3cc12</smiles>

PMDA<smiles>Cc1ccc(-n2c(=O)c3cc4c(=O)n(-c5ccc(OC(C)(C)C)cc5)c(=O)c4cc3c2=O)cc1</smiles>

The overall reaction for the PMDA-derived copolymer series is given in equation (A3) and the overall reaction for the BTDA-derived series is illustrated in equation (A4). 


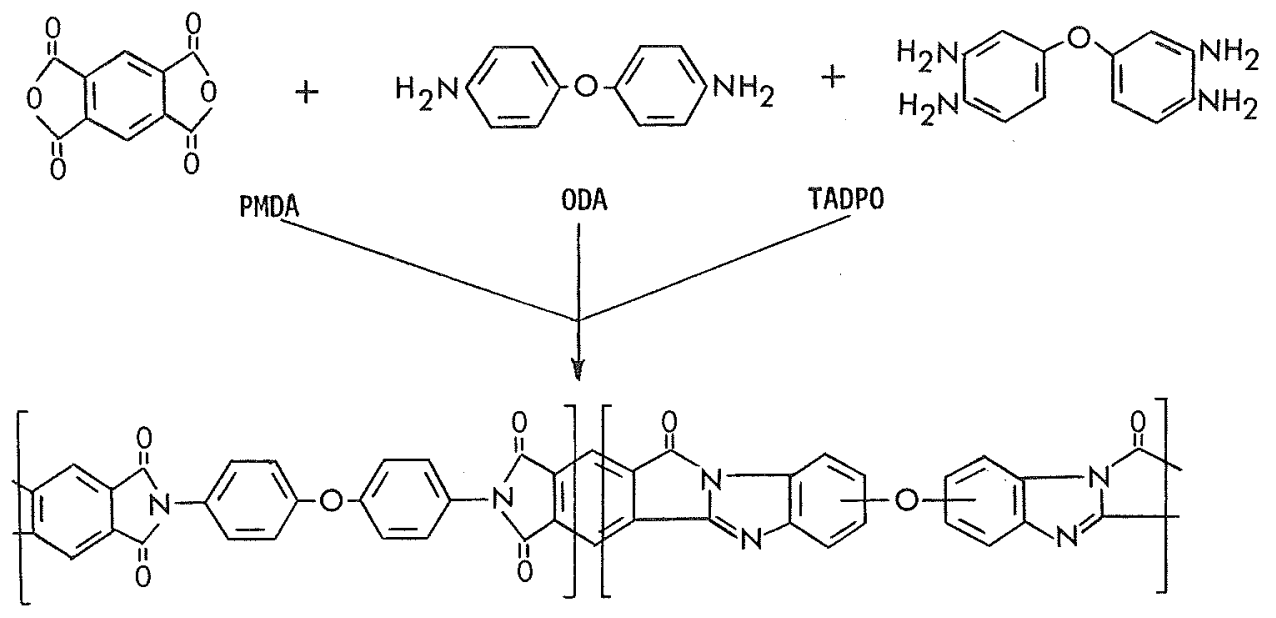

PMDA-0DA/TADPO $(100 / 0,90 / 10,75 / 25,50 / 50,25 / 75,0 / 100)$

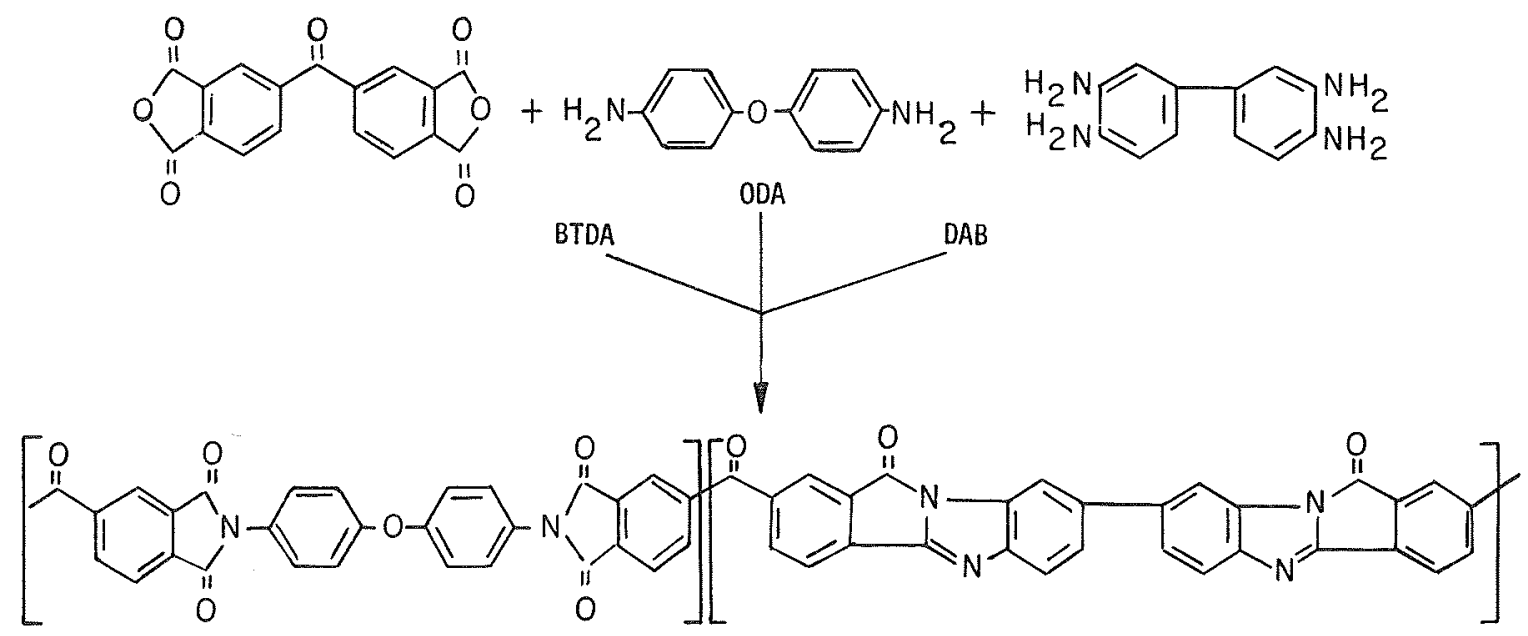

BTDA-ODA/DAB $(100 / 0,75 / 25,50 / 50,25 / 75,0 / 100)$ 


\section{APPENDIX B}

\section{PURIFICA TION OF MONOMERS}

Pyromellitic dianhydride was purified by vacuum sublimation at $498^{\circ}$ to $513^{\circ} \mathrm{K}\left(225^{\circ}\right.$ to $240^{\circ} \mathrm{C}$ ) and $0.5 \operatorname{torr}\left(66.5 \mathrm{~N} / \mathrm{m}^{2}\right) .3,3^{\prime}, 4,4^{\prime}$-Benzophenone tetracarboxylic dianhydride was purified by recrystallization from acetic anhydride. 3,3',4,4'-Tetraaminodiphenyl ether was synthesized and purified by a method described in references 7 and 11.

p,p'-Oxydianiline was purified by recrystallization from acetone, followed by sublimation at $458^{\circ} \mathrm{K}\left(185^{\circ} \mathrm{C}\right)$ and 0.5 torr $\left(66.5 \mathrm{~N} / \mathrm{m}^{2}\right)$. 3,3'-Diaminobenzidine was used as received from commercial sources. N,N-Dimethylacetamide was purified by distillation from pyromellitic dianhydride. 


\section{APPENDIX C}

\section{MEASUREMENT OF PROPERTIES}

Viscosity measurements were performed with Ubbelohde viscometers at $298^{\circ} \mathrm{K}$ $\left(25^{\circ} \mathrm{C}\right)$ in DMAc. The intrinsic viscosity was obtained from a four-point extrapolation to infinite dilution (ref. 8). Thermogravimetric analyses were performed by using a nullbalancing automatic-recording electrobalance (Cahn RG electrobalance) with 1-mil $(0.0254-\mathrm{mm})$ film samples weighing $2.05 \pm 0.03 \mathrm{mg}$ (ref. 9). The vacuum measurements were made at a pressure of $1 \times 10^{-6} \operatorname{torr}\left(1.33 \times 10^{-4} \mathrm{~N} / \mathrm{m}^{2}\right)$ maintained by an ion pump with a capacity of $250000 \mathrm{~cm} 3 / \mathrm{sec}$. Differential thermal analyses were made by using a Du Pont 900 Differential Thermal Analyzer (ref. 10).

The tensile stress-strain tests were performed with a Model TTC Instron Universal Tester on at least 10 separate 0.5 -inch-wide $(1.27-\mathrm{cm})$ strips of film by utilizing a 3.0 -inch $(7.62-\mathrm{cm})$ grip separation and a crosshead speed of $0.2 \mathrm{inch} / \mathrm{min}(0.51 \mathrm{~cm} / \mathrm{min})$. From the stress-strain curve, it was possible to determine the initial tangent modulus, the 0.2-percent offset.yield strength, and the tensile strength and elongation at break.

The moisture absorption was determined by exposing $2.0-\mathrm{mg}$ samples of $1 \mathrm{mil}$ $(0.0254-\mathrm{mm})$ film to alternate environments of 100 percent relative humidity at $298^{\circ} \mathrm{K}$ $\left(25^{\circ} \mathrm{C}\right)$ and zero percent relative humidity at $373^{\circ} \mathrm{K}\left(100^{\circ} \mathrm{C}\right)$. The following equation was used:

$$
\text { Percent of water }=\frac{\left(\text { Weight at } 100 \% \text { R.H., } 298^{\circ} \mathrm{K}\right)-\left(\text { Weight at } 0 \% \text { R.H., } 373^{\circ} \mathrm{K}\right)}{\text { Weight at } 0 \% \text { R.H., } 373^{\circ} \mathrm{K}} \times 100
$$




\section{REFERENCES}

1. Bower, G. M.; and Frost, L. W.: Aromatic Polyimides. J. Polymer Sci., pt. A, vol. 1 , no. 10, Oct. 1963, pp. 3135-3150.

2. Sroog, C. E.; Endrey, A. L.; Abramo, S. V.; Berr, C. E.; Edwards, W. M.; and Olivier, K. L.: Aromatic Polypyromellitimides From Aromatic Polyamic Acids. J. Polymer Sci., pt. A, vol. 3, no. 4, Apr. 1965, pp. 1373-1390.

3. Bell, Vernon L.; and Pezdirtz, George F.: Polyimidazopyrrolones: A New Route to Ladder Polymers. J. Polymer Sci., Pt. B, vol. 3, no. 12, Dec. 1965, pp. 977-984.

4. Dawans, F.; and Marvel, C. S.: Polymers From Ortho Aromatic Tetraamines and Aromatic Dianhydrides. J. Polymer Sci., Pt. A, vol. 3, no. 10, Oct. 1965, pp. 3549-3571.

5. Colson, J. G.; Michel, R. H.; and Paufler, R. M.: Polybenzoylenebenzimidazoles. J. Polymer Sci., Pt. A-1, vol. 4, no. 1, Jan. 1966, pp. 59-70.

6. Van Deusen, R. L.: Benzimidazo-Benzophenanthroline Polymers. J. Polymer Sci., Pt. B, vol. 4, no. 3, Mar. 1966, pp. 211-214.

7. Bell, Vernon L.; and Jewell, Robert A.: Synthesis and Properties of Polyimidazopyrrolones. J. Polymer Sci., Pt. A-1, vol. 5, no. 12, Dec. 1967, pp. 3043-3060.

8. Flory, Paul J.: Principles of Polymer Chemistry. Cornell Univ. Press, 1953, pp. 308-316.

9. Jewell, Robert A.: Thermal Degradation Studies of Several Pyrrone Films. J. Appl. Polymer Sci., vol. 12, no. 5, May 1968, pp. 1137-1145.

10. Sorenson, Wayne R.; and Campbell, Tod W.: Preparative Methods of Polymer Chemistry. Second ed., Interscience Publ., c.1968, p. 52.

11. Foster, Robbie T.; and Marvel, C. S.: Polybenzimidazoles. IV. Polybenzimidazoles Containing Aryl Ether Linkages. J. Polymer Sci., Pt. A, vol. 3, no. 2, Feb. 1965, pp. $417-421$. 
TABLE I.- SUMMARY OF POLYMERIZATIONS FOR PMDA-ODA/TADPO COPOLYMERS

\begin{tabular}{|c|c|c|c|c|c|}
\hline \multirow{2}{*}{$\begin{array}{c}\text { ODA/TADPO } \\
\text { ratio }\end{array}$} & \multicolumn{3}{|c|}{ Reactants } & Solvent (DMAc), \\
\cline { 2 - 5 } & $\begin{array}{c}\text { ODA, } \\
\text { millimoles }\end{array}$ & $\begin{array}{c}\text { TADPO, } \\
\text { millimoles }\end{array}$ & $\begin{array}{c}\text { PMDA, } \\
\text { millimiscosics } \\
\text { viscosity, } \\
\text { dl/g }\end{array}$ \\
\hline $100 / 0$ & 20.0 & -- & 20.8 & 74 & 1.47 \\
$90 / 10$ & 18.0 & 2.0 & 20.8 & 75 & 1.65 \\
$75 / 25$ & 15.0 & 5.0 & 20.8 & 75 & 2.55 \\
$50 / 50$ & 10.0 & 10.0 & 20.6 & 75 & 2.78 \\
$25 / 75$ & 5.0 & 15.0 & 21.1 & 75 & 1.08 \\
$0 / 100$ & $--\infty$ & 20.0 & 21.0 & 75 & .99 \\
\hline
\end{tabular}

TABLE II.- SUMMARY OF POLYMERIZATIONS FOR BTDA-ODA/DAB COPOLYMERS

\begin{tabular}{|c|c|c|c|c|c|}
\hline \multirow{2}{*}{$\begin{array}{c}\text { ODA/DAB } \\
\text { ratio }\end{array}$} & $\begin{array}{c}\text { ODA, } \\
\text { millimoles }\end{array}$ & $\begin{array}{c}\text { DAB, } \\
\text { millimoles }\end{array}$ & $\begin{array}{c}\text { BTDA, } \\
\text { millimoles }\end{array}$ & $\begin{array}{c}\text { Solvent (DMAc), } \\
\mathrm{cm}^{3}\end{array}$ & $\begin{array}{c}\text { Intrinsic } \\
\text { viscosity, } \\
\mathrm{dl} / \mathrm{g}\end{array}$ \\
\hline $100 / 0$ & 20.0 & --- & 20.5 & 60 & 1.05 \\
$75 / 25$ & 15.0 & 5.0 & 20.2 & 60 & 1.18 \\
$50 / 50$ & 10.0 & 10.0 & 20.2 & 60 & 1.28 \\
$25 / 75$ & 5.0 & 15.0 & 20.1 & 60 & .85 \\
$0 / 100$ & $-\cdots-$ & 20.0 & 20.1 & 60 & .83 \\
\hline
\end{tabular}

TABLE III. - MECHANICAL PROPERTIES OF PMDA-ODA/TADPO COPOLYMER FILMS

\begin{tabular}{|c|c|l|c|c|c|c|c|}
\hline \multirow{2}{*}{ Copolymer composition } & \multicolumn{2}{|c|}{$\begin{array}{c}\text { Tangent } \\
\text { modulus }\end{array}$} & \multirow{2}{*}{$\begin{array}{c}\text { Elongation } \\
\text { percent }\end{array}$} & \multicolumn{3}{|c|}{ Yield } & \multicolumn{3}{c|}{ Tensile } \\
\cline { 2 - 5 } \cline { 5 - 8 } & $\mathrm{ksi}$ & $\mathrm{N} / \mathrm{m}^{2}$ & & $\mathrm{ksi}$ & $\mathrm{N} / \mathrm{m}^{2}$ & $\mathrm{ksi}$ & $\mathrm{N} / \mathrm{m}^{2}$ \\
\hline PMDA-ODA/TADPO (100/0) & 344 & $237 \times 10^{7}$ & 7.7 & 4.6 & $3.2 \times 10^{7}$ & 11.3 & $7.8 \times 10^{7}$ \\
PMDA-ODA/TADPO (90/10) & 405 & 279 & 7.9 & 6.1 & 4.2 & 13.9 & 9.6 \\
PMDA-ODA/TADPO (75/25) & 502 & 346 & 4.7 & 8.6 & 5.9 & 14.7 & 10.1 \\
PMDA-ODA/TADPO (50/50) & 415 & 286 & 4.3 & 8.8 & 6.1 & 14.1 & 9.7 \\
PMDA-ODA/TADPO (25/75) & 589 & 406 & 3.4 & 10.7 & 7.4 & 14.0 & 9.6 \\
PMDA-ODA/TADPO (0/100) & 623 & 429 & 3.1 & 11.4 & 7.9 & 14.3 & 9.9 \\
\hline
\end{tabular}


TABLE IV.- MECHANICAL PROPERTIES OF BTDA-ODA/DAB COPOLYMER FILMS

\begin{tabular}{|c|c|c|c|c|c|c|c|}
\hline \multirow{3}{*}{ Copolymer composition } & \multirow{2}{*}{\multicolumn{2}{|c|}{$\begin{array}{l}\text { Tangent } \\
\text { modulus }\end{array}$}} & \multirow{3}{*}{$\begin{array}{c}\text { Elongation, } \\
\text { percent }\end{array}$} & \multicolumn{4}{|c|}{ Strength } \\
\hline & & & & \multicolumn{2}{|c|}{ Yield } & \multicolumn{2}{|c|}{ Tensile } \\
\hline & ksi & $\mathrm{N} / \mathrm{m}^{2}$ & & ksi & $\mathrm{N} / \mathrm{m}^{2}$ & ksi & $\mathrm{N} / \mathrm{m}^{2}$ \\
\hline BTDA-ODA/DAB $(100 / 0)$ & 376 & $259 \times 10^{7}$ & 5.2 & 8.7 & $6.0 \times 10^{7}$ & 12.4 & $8.5 \times 10^{7}$ \\
\hline BTDA-ODA/DAB $(75 / 25)$ & 444 & 306 & 4.7 & 10.3 & 7.1 & 14.7 & 10.1 \\
\hline BTDA-ODA/DAB $(50 / 50)$ & 443 & 305 & 5.0 & 9.7 & 6.7 & 14.2 & 9.8 \\
\hline BTDA-ODA/DAB $(25 / 75)$ & 569 & 392 & 3.5 & 13.3 & 9.2 & 16.0 & 11.0 \\
\hline BTDA-ODA/DAB $(0 / 100)$ & 588 & 405 & 3.7 & 12.9 & 8.9 & 17.3 & 11.9 \\
\hline
\end{tabular}

TABLE V. - EFFECT OF CAUSTIC AND ACIDIC REAGENTS ON PMDA-ODA/TADPO COPOLYMER FILMS ${ }^{\mathrm{a}}$

\begin{tabular}{|l|c|c|c|}
\hline \multicolumn{1}{|c|}{ Copolymer composition } & $2 \mathrm{~N} \mathrm{NaOH}$ & $96 \% \mathrm{H}_{2} \mathrm{SO}_{4}$ & Fuming $\mathrm{HNO}_{3}$ \\
\hline PMDA-ODA/TADPO (100/0) & $\begin{array}{c}\text { Gelled mass } \\
\text { in } 0.5 \mathrm{hr} \\
\text { Film intact for } \\
\text { over } 48 \mathrm{hr}\end{array}$ & $\begin{array}{c}\text { Gelled mass } \\
\text { in } 1.0 \mathrm{hr} \\
\text { Film intact for } \\
\text { over } 48 \mathrm{hr}\end{array}$ & $\begin{array}{c}\text { Dissolved in } \\
0.5 \mathrm{hr} \\
\text { Dissolved in } \\
24 \text { to } 48 \mathrm{hr} \\
\text { PMDA-ODA/TADPO (90/10) }\end{array}$ \\
PMDA-ODA/TADPO (75/25,50/50,25/75) & $\mid \begin{array}{c}\text { Film intact for } \\
\text { over } 48 \mathrm{hr}\end{array}$ \\
\hline
\end{tabular}

a Tests performed on $1-\mathrm{mil} \quad(0.0254-\mathrm{mm})$ films at room temperature. 

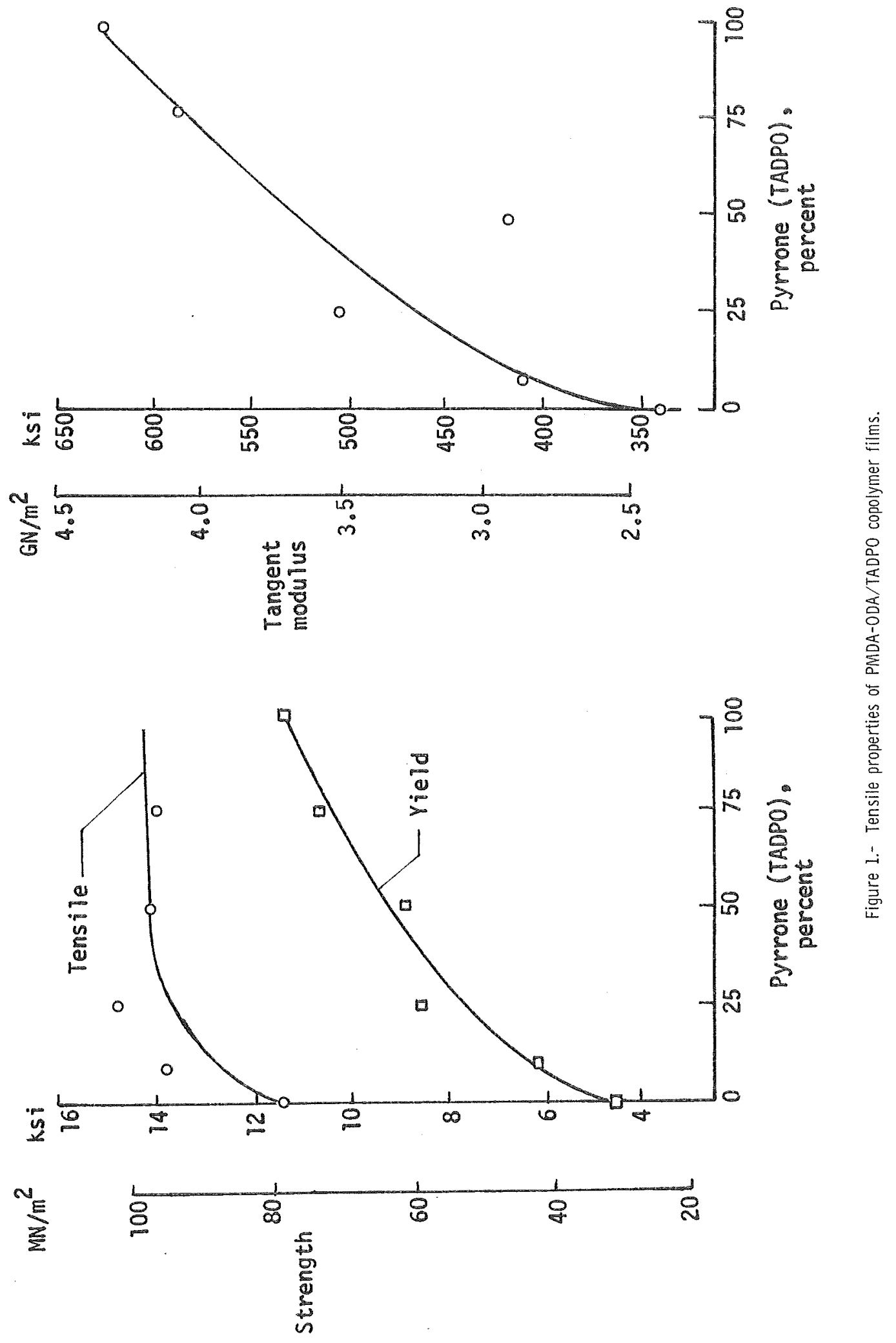

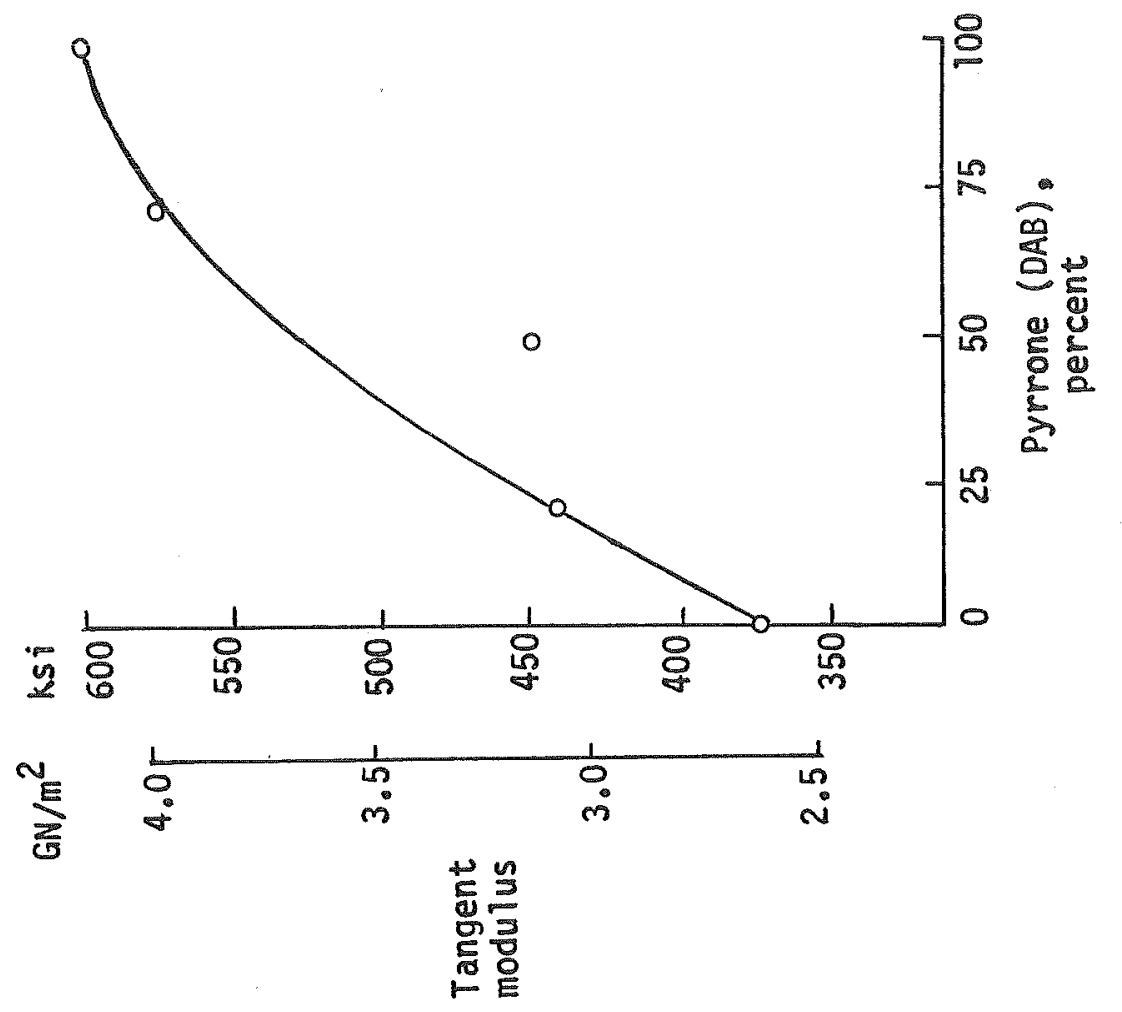

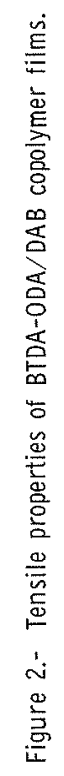

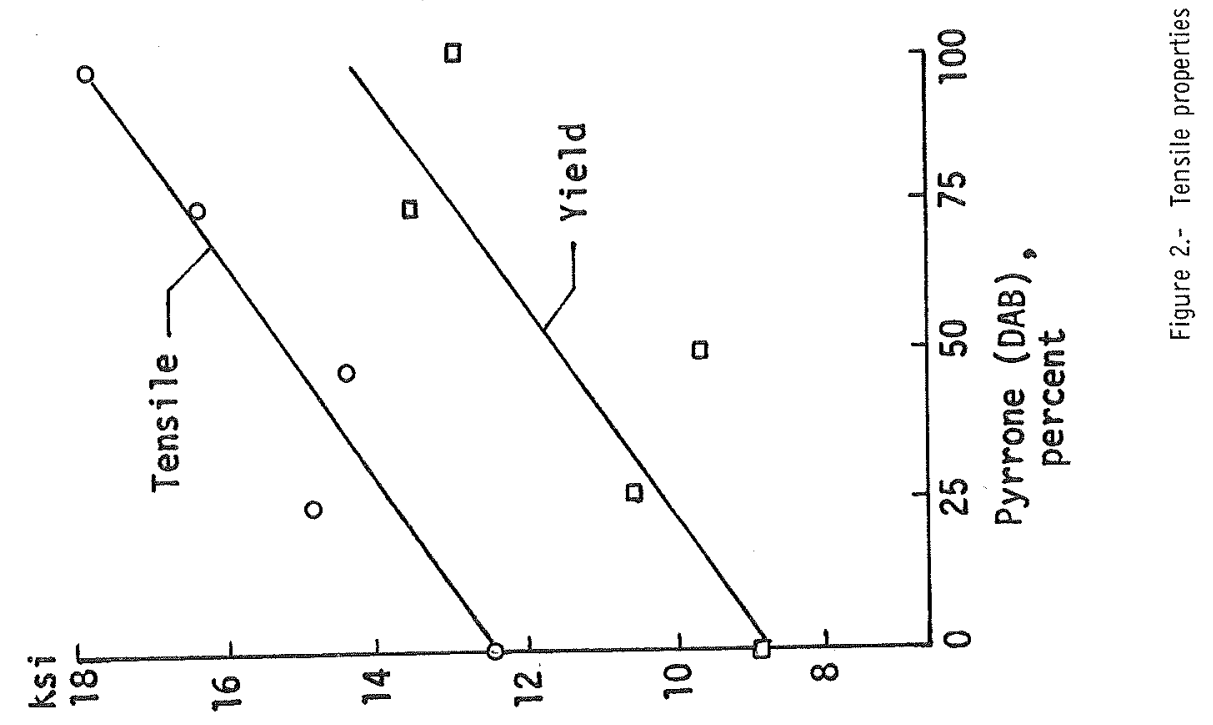

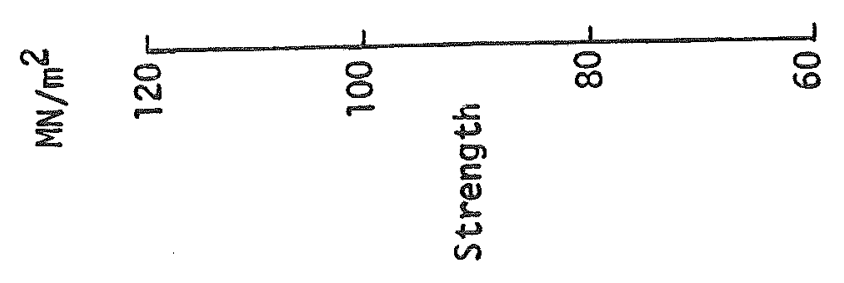




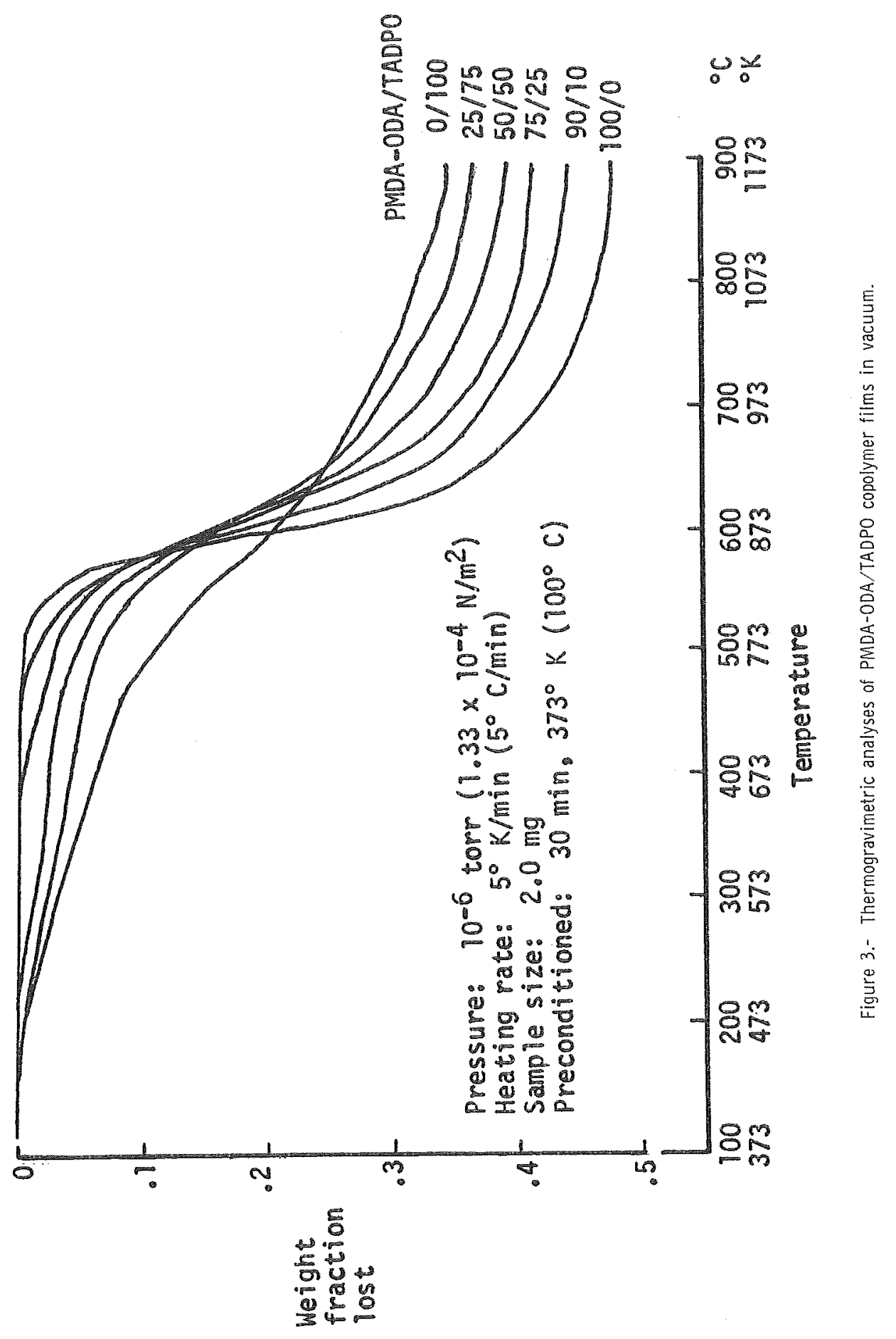




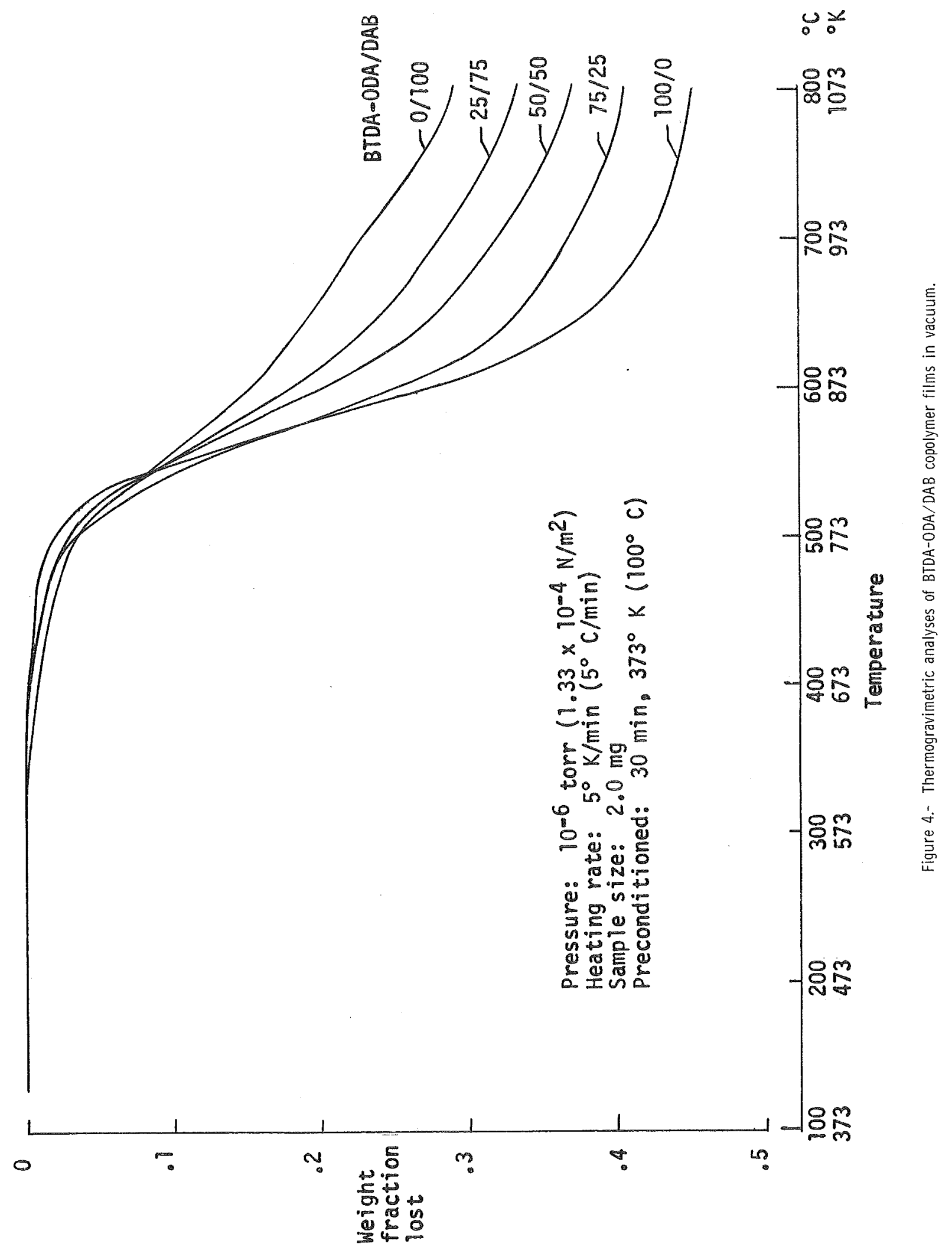




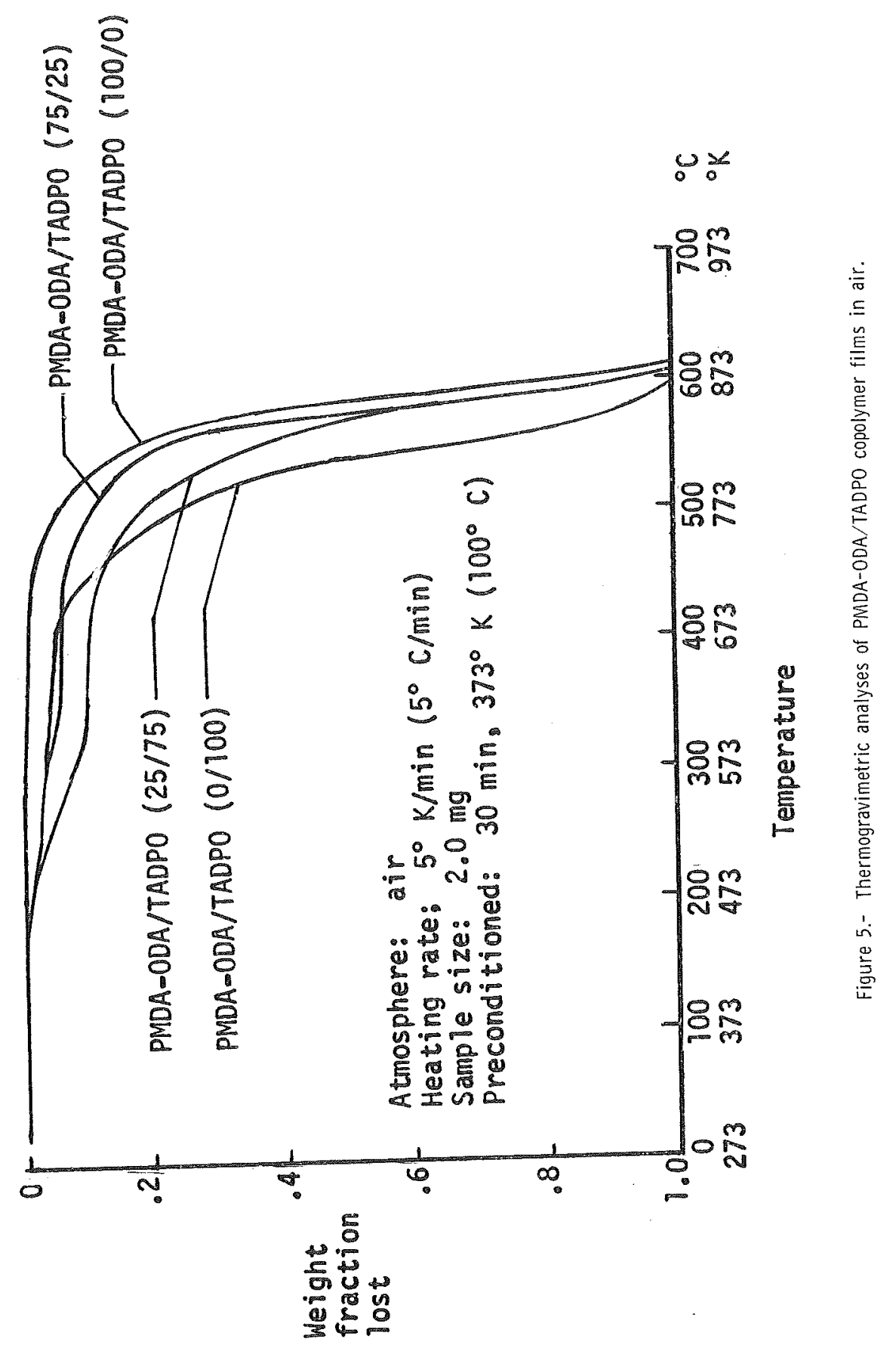




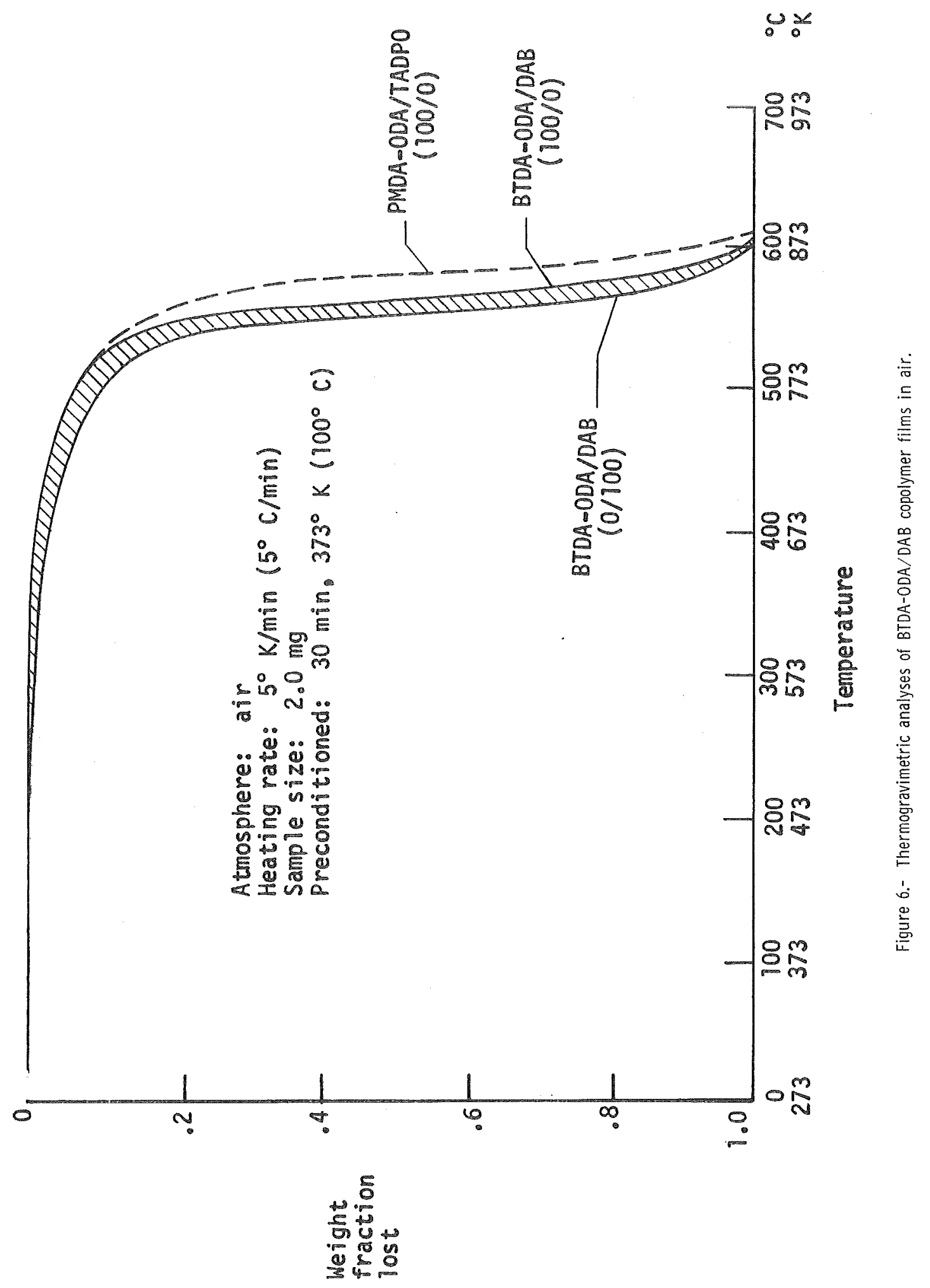




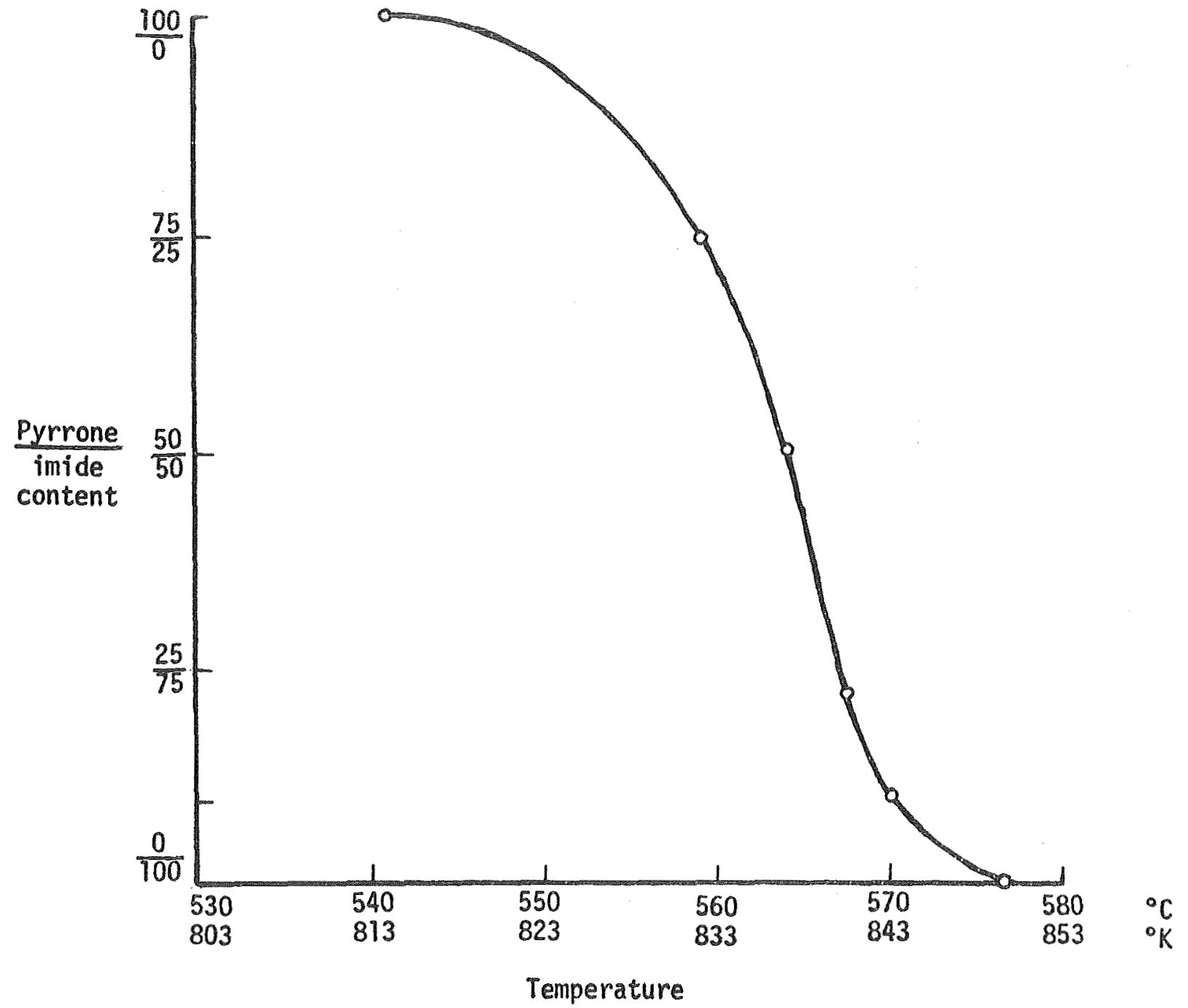

Figure 7.- Temperatures of maximum rates of decomposition in air of PMDA-ODA/TADPO copolymer films as a function of Pyrrone/imide content. 


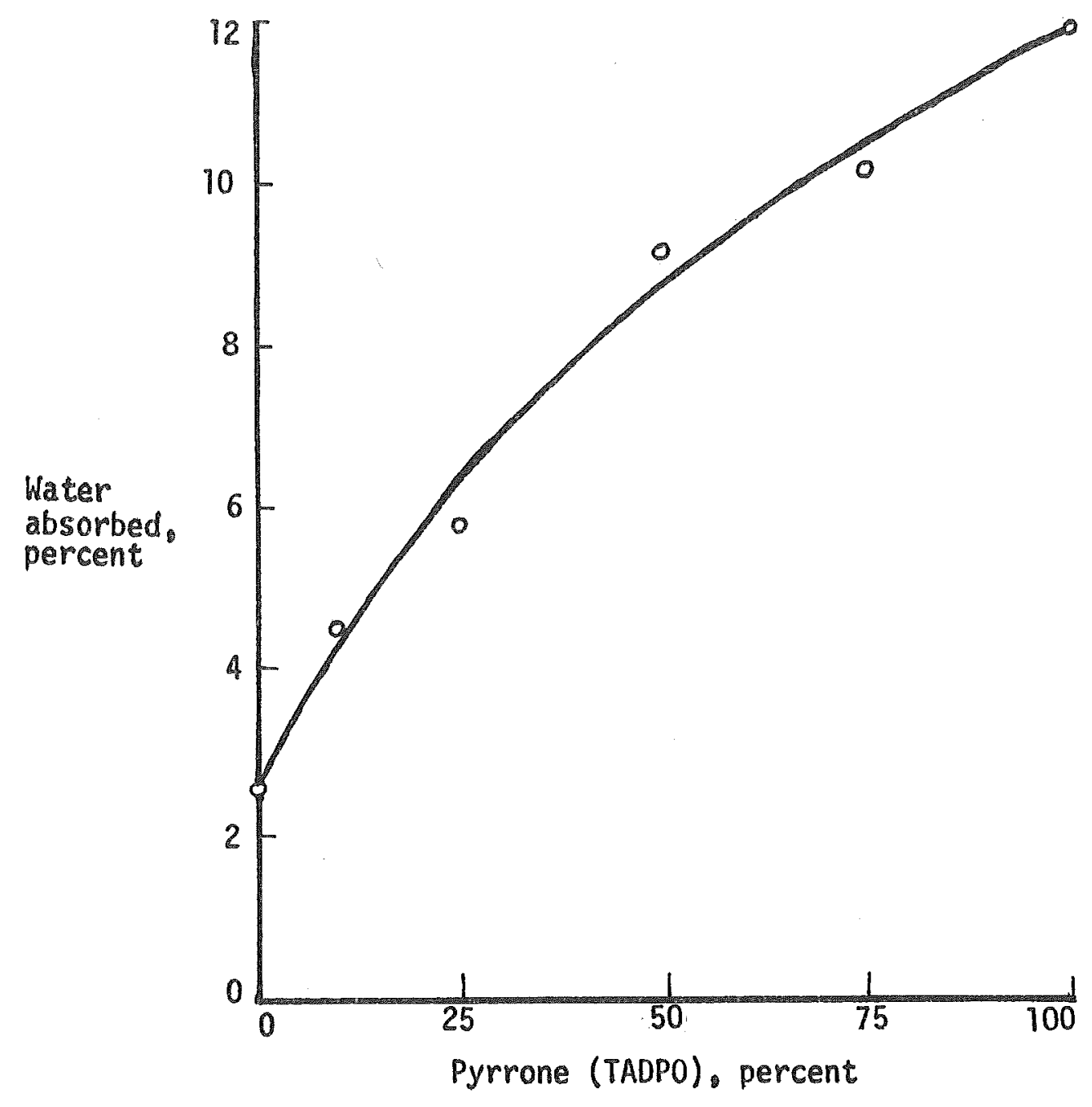

Figure 8.- Percentage water absorption by PMDA-ODA/TADPO copolymer films. 


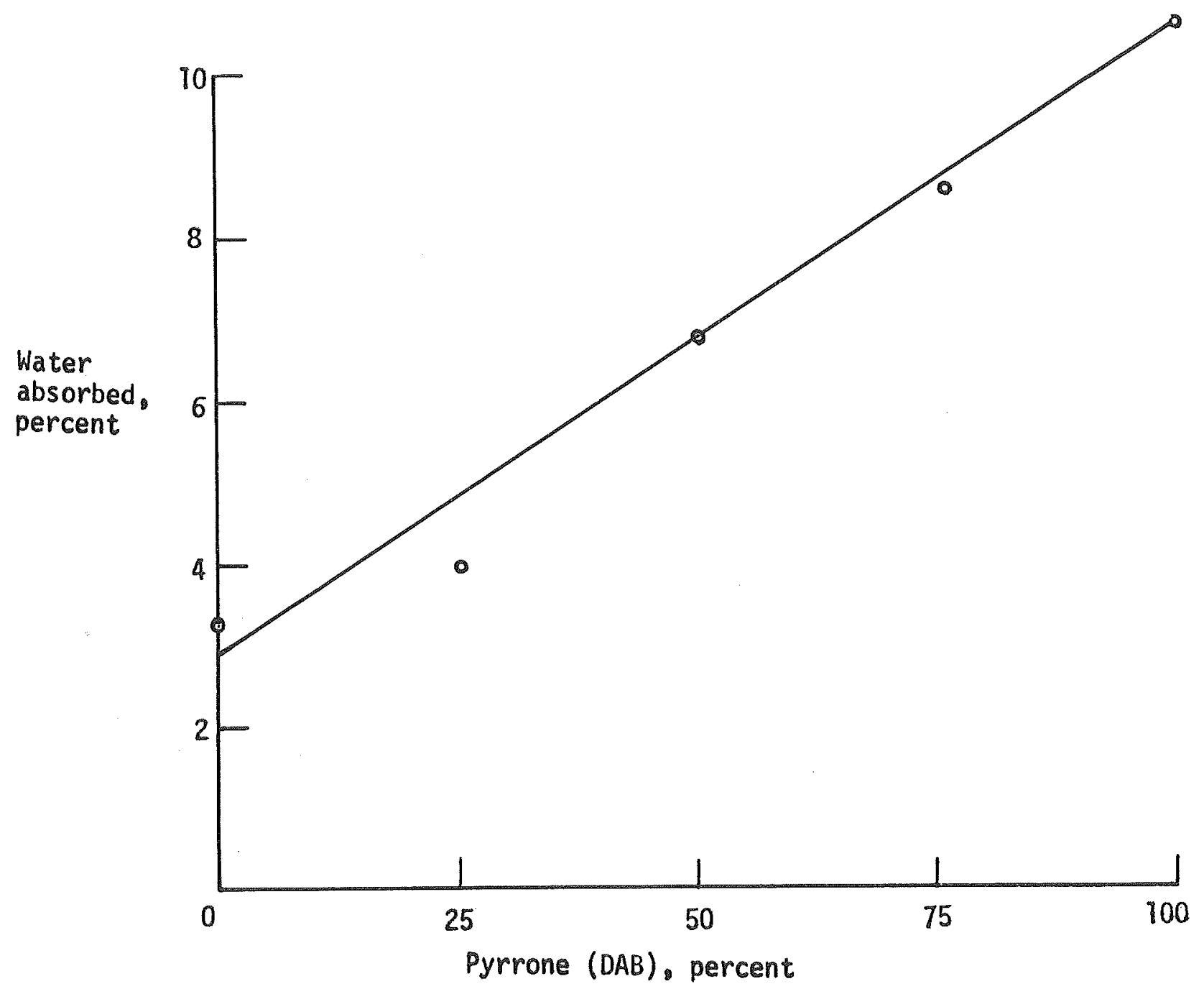

Figure 9.- Percentage water absorption by BTDA-ODA/DAB copolymer films. 


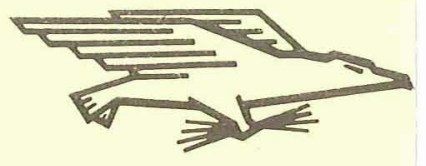

POSTAGE AND FEES PAID NATIONAL AERONAUTICS AND SPACE ADMINISTRATION

"The aeronatitical and space activities of the United States shall be conducted so as to contribute. . . to the expansion of human knowledge of phenomena in the atmosphere and space. The Administration shall provide for the widest practicable and appropriate dissemination of information concerning its activities and the results thereof."

\section{NASA SCIENTIFIC AND TECHNICAL PUBLICATIONS}

TECHNICAL REPORTS: Scientific and technical information considered important, complete, and a lasting contribution to existing knowledge.

TECHNICAL NOTES: Information less broad in scope but nevertheless of importance as a contribution to existing knowledge.

TECHNICAL MEMORANDUMS:

Information receiving limited distribution because of preliminary data, security classification, or other reasons.

CONTRACTOR REPORTS: Scientific and technical information generated under a NASA contract or grant and considered an important contribution to existing knowledge.
TECHNICAL TRANSLATIONS: Information published in a foreign language considered to merit NASA distribution in English.

SPECIAL PUBLICATIONS: Information derived from or of value to NASA activities. Publications include conference proceedings, monographs, data compilations, handbooks, sourcebooks, and special bibliographies.

\section{TECHNOLOGY UTILIZATION}

PUBLICATIONS: Information on technology used by NASA that may be of particular interest in commercial and other non-aerospace applications. Publications include Tech Briefs, Technology Utilization Reports and Notes, and Technology Surveys.

Details on the availability of these publications may be obtained from:

SCIENTIFIC AND TECHNICAL INFORMATION DIVISION

NATIONAL AERONAUTICS AND SPACE ADMINISTRATION

Washington, D.C. 20546 